\title{
Editorial: Zebrafish Cognition and Behavior
}

\author{
Ana Carolina Luchiari ${ }^{1 *}$, Edward Málaga-Trillo ${ }^{2}$, Steven Tran ${ }^{3}$ and Robert Gerlai ${ }^{4 *}$ \\ ${ }^{1}$ Department of Physiology and Behavior, Federal University of Rio Grande Do Norte, Natal, Brazil, ${ }^{2}$ Department of Biology, \\ Universidad Peruana Cayetano Heredia, Lima, Peru, ${ }^{3}$ Department of Biology and Biological Engineering, California Institute \\ of Technology, Pasadena, CA, United States, ${ }^{4}$ Department of Psychology, University of Toronto Mississauga, Mississauga, \\ ON, Canada
}

Keywords: behavior, learning, memory, fish, perception

\section{Editorial on the Research Topic}

\section{Zebrafish Cognition and Behavior}

Understanding animal cognition has been of interest to scientists for well over a century (e.g., Melrose, 1921). Cognition is broadly defined as the neural and behavioral processes associated with the acquisition, retention, and use of information (Dukas, 2004). Since the discovery of multiple memory systems and of the fundamental role of the hippocampus in relational learning and memory in humans (Penfield and Milner, 1958), one exciting focus of study has been to determine how animals encode, transform, compute and manipulate spatial, temporal, and contextual information from their environment, and how this information is utilized to organize

OPEN ACCESS

Edited by:

Walter Adriani,

National Institute of Health (ISS), Italy

Reviewed by:

Rui F. Oliveira,

University Institute of Psychological, Social and Life Sciences (ISPA), Portugal

*Correspondence:

Ana Carolina Luchiari analuchiari@yahoo.com.br Robert Gerla robert_gerlai@yahoo.com

Specialty section: This article was submitted to Individual and Social Behaviors, a section of the journal Frontiers in Behavioral Neuroscience

Received: 27 January 2021

Accepted: 24 February 2021

Published: 16 March 2021

Citation: Luchiari AC, Málaga-Trillo E, Tran S and Gerlai R (2021) Editorial: Zebrafish

Cognition and Behavior.

Front. Behav. Neurosci. 15:659501. doi: 10.3389/fnbeh.2021.659501 behavioral responses (Cook, 1993). Initial studies used simple visual and acoustic stimuli, such as colored lights and distinct sounds. However, the use of such stimuli hindered the study of animal cognition because it did not allow the subjects to fully engage their full information processing capabilities. To address this issue, researchers started using more complex stimuli, such as objects, photos, and videos. These studies demonstrated a higher level of cognitive processing not previously attributed to animals (Dukas, 2004). As the field of learning and memory advanced, studies started to show remarkable similarities between the cognitive processes of animals and humans. Animals have been found to be even able to learn varied and sophisticated concepts, exhibit mental processes, such as symbol coding and organization, to form spatial, temporal, and numerical abstractions and perceive cause and effect relationships (Wynne, 2001).

While it is widely accepted that mammals and birds have the capacity for complex cognitive processing, the cognitive abilities of certain less well-studied species were questioned and some species were assumed to be able to exhibit only simple stimulus-response reflexes. For example, even fundamental cognitive abilities of fish used to be debated with doubts about whether fish could learn and/or remember. Even in the not-so distant past, some assumed that fish were incapable of complex cognitive processing due to their relatively small and simple brain, and similarly, fish were assumed not to experience suffering but only to exhibit reflexive responses to risk and pain (Rose, 2002; Arlinghaus et al., 2007; Rose et al., 2014).

Although the brains of fish are indeed smaller and simpler, the genetic, neuronal, and physiological mechanisms that drive behavioral responses to a variety of stimuli are similar to those observed in mammals (Ito and Yamamoto, 2009; Klee et al., 2012; Gerlai, 2020). Furthermore, homologous brain regions that perform similar functions, for example, in the regulation of emotional states (dorsomedial pallium equivalent to the mammalian pallial amygdala), and learning and memory (dorsolateral pallium equivalent to the mammalian hippocampus) (Vargas et al., 2009) have been identified. Even the assertion that fish lack a brain area homologous to the mammalian cortex appears debatable (Mueller, 2012).

Many studies suggest that fish exhibit complex behavioral responses that cannot be explained as a simple "stimulus-response" reflex (Trotha et al., 2014; Rey et al., 2015). For instance, fish are 
capable of exhibiting tool-use like behavior (Kuba et al., 2010; Paśko, 2010; Millot et al., 2014; Brown, 2015), spatial learning (Salas et al., 1996; Sison and Gerlai, 2010; Karnik and Gerlai, 2012; Luchiari et al., 2015), counting (Agrillo et al., 2007, 2008, 2009, 2012), and possess long-term memory (Hinz et al., 2013). In fact, some even suggests that given the neurobiological prerequisites, physiological, anatomical, synaptic, and molecular mechanism related characteristics, as well as behavioral level phenomena, fish may have some level of sentience (Gerlai, 2017; Woodruff, 2017; also see Cerqueira et al., 2020).

Among the many fish species that have contributed to the current knowledge on fish cognition and behavior, the zebrafish, a small teleost fish native to South Asia, stands out as an important vertebrate model in biomedical research. Zebrafish have been used in the fields of embryology (Kimmel et al., 1995; Pinheiroda-Silva and Luchiari, in press), toxicology (Coe et al., 2009; Oliveira et al., 2009; Dai et al., 2014), genetics (Driever et al., 1994; Liu et al., 2019), pharmacology (Goldsmith, 2004; Barros et al., 2008) mainly because this species is believed to offer translational relevance in biomedical research (Kalueff et al., 2014; Stewart et al., 2014). One of the first studies on zebrafish genetics was performed by George Streisinger in the 70's. Streisinger and colleagues from the University of Oregon successfully generated the first homozygous diploid zebrafish clones (Streisinger et al., 1981), one of the earliest registries of a vertebrate clone.

The many advantages of zebrafish drew the attention of other researchers, especially those who were interested in embryonic development. The main advantage for embryologists was that zebrafish embryos are transparent, which allowed visualization of changes in anatomical structures during ontogenesis. An additional attractive aspect of zebrafish development is that it is very fast: the embryos hatch after 3 days post-fertilization. This fast development has been leveraged in a variety of disciplines from genetics to toxicology and teratology.

At present, although precise figures are lacking, an estimated 8 million zebrafish are being used every year in more than 600 laboratories worldwide, making this species one of the most popular laboratory animals for translational research. In 2000, the zebrafish genome was partially sequenced (Barbazuk et al., 2000), allowing more detailed understanding of the genetic similarities between zebrafish and other vertebrates, including humans. With increasing interest from laboratories worldwide on studying zebrafish cognition, the use of zebrafish translational research also increased. Many questions have arisen including how one can improve cognition, whether it be through exercise or pharmacotherapy, and why cognitive function decays under certain situations, such as sleep deprivation or some brain diseases. Although fish are more distantly related to humans compared to other mammalian models, their simple brain possessing numerous evolutionarily conserved features as

\section{REFERENCES}

Agrillo, C., Dadda, M., and Bisazza, A. (2007). Quantity discrimination in female mosquitofish. Anim. Cogn. 10, 63-70. doi: 10.1007/s10071-0060036-5 well as their rich behavioral repertoire make them a powerful animal model for investigating mechanisms underlying complex behaviors, such as learning and memory (Gerlai, 2020).

Several behavioral responses are the result of cognitive processes, which depend upon structural, physiological, and biochemical characteristics of the central nervous system. These characteristics can be investigated at multiple levels of analysis starting with biochemical interactions all the way to the connectome, remodeling of neural pathways. In this regard, the zebrafish offers the complexity of a vertebrate brain combined with the simplicity and practicality of invertebrates which can utilize classical behavioral and electrophysiological and neurobiological studies along with the latest advancement in proteomics and genetics.

The Research Topic "Zebrafish Cognition and Behavior" in Frontiers in Behavioral Neuroscience samples this rich and fast evolving field, and provides examples on how cognitive function may be studied using this simple vertebrate at multiple organizational levels, from molecules to behavior, and from health to pathology. For example, Pita and Fernández-Juricic explores how shoaling, a complex and dynamic behavior, is influenced by a variety of environmental factors, while Facciol and Gerlai reviews the growing literature on the neurobiological mechanisms underlying shoaling and how this behavior may be affected by embryonic alcohol exposure. Menezes et al. study the behavioral consequences of stress induced by exposure of juvenile zebrafish to abnormally aggressive large male zebrafish. Luz et al. shows that pharmacological intervention using a CB1 receptor agonist counteracts acute restraint-stress induced anxiety-like behaviors, oxidative stress and GABA neurotransmitter level decrease in zebrafish. Gusso et al. shows how an environmental toxicant, pyriproxyfen, impairs memory and cortisol levels in zebrafish. Gómez-Laplaza and Gerlai, studies quantity estimation abilities and the role of different features of food items in decision making in fish using the freshwater angelfish. Daniel and Bhat studies correlations between personality and cognitive traits in zebrafish. Last, Buatois and Gerlai explores often controversial questions concerning elemental vs. configural learning and memory in fish, with a particular focus on zebrafish.

\section{AUTHOR CONTRIBUTIONS}

All authors listed have made a substantial, direct and intellectual contribution to the work, and approved it for publication.

\section{FUNDING}

RG was supported by NSERC Discovery Grant (No. 311637) and University of Toronto Distinguished Professorship Award.

Agrillo, C., Dadda, M., Serena, G., and Bisazza, A. (2008). Do fish count? Spontaneous discrimination of quantity in female mosquitofish. Anim. Cogn. 11, 495-503. doi: 10.1007/s10071-008-0140-9

Agrillo, C., Dadda, M., Serena, G., and Bisazza, A. (2009). Use of number by fish. PLoS ONE 4:e4786. doi: 10.1371/journal.pone.0004786 
Agrillo, C., Piffer, L., Bisazza, A., and Butterworth, B. (2012). Evidence for two numerical systems that are similar in humans and guppies. PLOS ONE 7:e31923. doi: 10.1371/journal.pone.0031923

Arlinghaus, R., Cooke, S. J., Lyman, J., Policansky, D., Schwab, A., Suski, C., et al. (2007). Understanding the complexity of catch-and-release in recreational fishing: an integrative synthesis of global knowledge from historical, ethical, social, and biological perspectives. Rev. Fish Sci. 15, 75-167. doi: 10.1080/10641260601149432

Barbazuk, W. B., Korf, I., Kadavi, C., Heyen, J., Tate, S., Wun, E., et al. (2000). The syntenic relationship of the zebrafish and human genomes. Gen. Res. 10, 1351-1358. doi: 10.1101/gr.144700

Barros, T. P., Alderton, W. K., Reynolds, H. M., Roach, A. G., and Berghmans, S. (2008). Zebrafish: an emerging technology for in vivo pharmacological assessment to identify potential safety liabilities in early drug discovery. Br. J. Pharmacol. 154, 1400-1413. doi: 10.1038/bjp.2008.249

Brown, C. (2015). Fish intelligence, sentience and ethics. Anim. Cogn. 18, 1-17. doi: 10.1007/s10071-014-0761-0

Cerqueira, M., Millot, S., Felix, A., Silva, T., Oliveira, G. A., Oliveira, C. C., et al. (2020). Cognitive appraisal in fish: stressor predictability modulates the physiological and neurobehavioural stress response in sea bass. Proc. Ro. Soc. $B$ 287:20192922. doi: 10.1098/rspb.2019.2922

Coe, T. S., Hamilton, P. B., Griffiths, A. M., Hodgson, D. J., Wahab, M. A., and Tyler, C. R. (2009). Genetic variation in strains of zebrafish (Danio rerio) and the implications for ecotoxicology studies. Ecotoxicology 18, 144-150. doi: 10.1007/s10646-008-0267-0

Cook, R. G. (1993). The experimental analysis of cognition in animals. Psychol. Sci. 4, 174-178. doi: 10.1111/j.1467-9280.1993.tb00483.x

Dai, Y. J., Jia, Y. F., Chen, N., Bian, W. P., Li, Q. K., Ma, Y. B., et al. (2014). Zebrafish as a model system to study toxicology. Envi. Toxicol. Chem. 33, 11-17. doi: $10.1002 /$ etc. 2406

Driever, W., Stemple, D., Schier, A., and Solnica-Krezel, L. (1994). Zebrafish: genetic tools for studying vertebrate development. Trends Gen. 10, 152-159. doi: 10.1016/0168-9525(94)90091-4

Dukas, R. (2004). Evolutionary biology of animal cognition. Annu. Rev. Ecol. Evol. Syst. 35, 347-374. doi: 10.1146/annurev.ecolsys.35.112202.130152

Gerlai, R. (2017). Learning, memory, cognition and the question of sentience in fish. Invited Commentary. Anim. Sent. 13, 1-4. doi: 10.51291/2377-7478.1242

Gerlai, R. (2020). Evolutionary conservation, translational relevance and cognitive function: the future of zebrafish in behavioral neuroscience. Neurosci. Biobeh. Rev. 116, 426-435. doi: 10.1016/j.neubiorev.2020.07.009

Goldsmith, P. (2004). Zebrafish as a pharmacological tool: the how, why and when. Cur. Op. Pharmacol. 4, 504-512. doi: 10.1016/j.coph.2004.04.005

Hinz, F. I., Aizenberg, M., Tushev, G., and Schuman, E. M. (2013). Protein synthesis-dependent associative long-term memory in larval zebrafish. $J$ Neurosci. 33, 15382-15387. doi: 10.1523/JNEUROSCI.0560-13.2013

Ito, H., and Yamamoto, N. (2009). Non-laminar cerebral cortex in teleost fishes? Biol. Lett. 5, 117-121. doi: 10.1098/rsbl.2008.0397

Kalueff, A. V., Stewart, A. M., and Gerlai, R. (2014). Zebrafish as an emerging model for studying complex brain disorders. Trends Pharmacol. Sci. 35, 63-75. doi: 10.1016/j.tips.2013.12.002

Karnik, I., and Gerlai, R. (2012). Can zebrafish learn spatial tasks? An empirical analysis of place and single CS-US associative learning. Behav. Brain Res. 233, 415-421. doi: 10.1016/j.bbr.2012.05.024

Kimmel, C. B., Ballard, W. W., Kimmel, S. R., Ullmann, B., and Schilling, T. F. (1995). Stages of embryonic development of the zebrafish. Dev. Dyn. 203, 253-310. doi: 10.1002/aja.1002030302

Klee, E. W., Schneider, H., Clark, K. J., Cousin, M. A., Ebbert, J. O., Hooten, W. M., et al. (2012). Zebrafish: a model for the study of addiction genetics. Hum. Genet. 131, 977-1008. doi: 10.1007/s00439-011-1128-0

Kuba, M. J., Byrne, R. A., and Burghardt, G. M. (2010). A new method for studying problem solving and tool use in stingrays (Potamotrygon castexi). Anim. Cogn. 13, 507-513. doi: 10.1007/s10071-009-0301-5

Liu, K., Petree, C., Requena, T., Varshney, P., and Varshney, G. K. (2019). Expanding the CRISPR toolbox in zebrafish for studying development and disease. Front. Cell Dev. Biol. 7:13. doi: 10.3389/fcell.2019.00013
Luchiari, A. C., Salajan, D. C., and Gerlai, R. (2015). Acute and chronic alcohol administration: effects on performance of zebrafish in a latent learning task. Behav. Brain Res. 282, 76-83. doi: 10.1016/j.bbr.2014. 12.013

Melrose, J. A. (1921). The structure of animal learning. Psychol. Rev. 28, 189-221.

Millot, S., Péan, S., Labbé, L., Kerneis, T., Quillet, E., Dupont-Nivet, M., et al. (2014). Assessment of genetic variability of fish personality traits using rainbow trout isogenic lines. Behav. Genet. 44, 383-393. doi: 10.1007/s10519-0149652-z

Mueller, T. (2012). What is the thalamus in zebrafish? Front. Neurosci. 6:64 doi: 10.3389/fnins.2012.00064

Oliveira, R., Domingues, I., Grisolia, C. K., and Soares, A. M. (2009). Effects of triclosan on zebrafish early-life stages and adults. Envi. Sci. Poll. Res. 16, 679-688. doi: 10.1007/s11356-009-0119-3

Paśko, Ł. (2010). Tool-like behavior in the sixbar wrasse, Thalassoma Hardwicke (Bennett, 1830). Zool. Biol. 29, 767-773. doi: 10.1002/zoo.20307

Penfield, W., and Milner, B. (1958). Memory deficit produced by bilateral lesions in the hippocampal zone. AMA Arch. Neurol. Psychiatry 79, 475-497. doi: 10.1001/archneurpsyc.1958.02340050003001

Pinheiro-da-Silva, J., and Luchiari, A. C. (in press). Embryonic ethanol exposure on zebrafish early development. Brain Behav. doi: 10.1002/brb3.2062

Rey, S., Huntingford, F. A., Boltana, S., Vargas, R., Knowles, T. G., and Mackenzie, S. (2015). Fish can show emotional fever: stress-induced hyperthermia in zebrafish. Proc. R. Soc. B 282:1819. doi: 10.1098/rspb.201 5.2266

Rose, J. D. (2002). The neurobehavioral nature of fishes and the question of awareness and pain. Rev. Fish Sci. 10, 1-38. doi: 10.1080/20026491051668

Rose, J. D., Arlinghaus, R., Cooke, S. J., Diggles, B. K., Sawynok, W., Stevens, E. D., et al. (2014). Can fish really feel pain? Fish Fish. 15, 97-133. doi: $10.1111 /$ faf.12010

Salas, C., Rodríguez, F., Vargas, J. P., Durán, E., and Torres, B. (1996). Spatial learning and memory deficits after telencephalic ablation in goldfish trained in place and turn maze procedures. Behav. Neurosci. 110, 965-980. doi: 10.1037/0735-7044.110.5.965

Sison, M., and Gerlai, R. (2010). Associative learning in zebrafish (Danio rerio) in the plus maze. Behav. Brain Res. 207, 99-104. doi: 10.1016/j.bbr.2009.09.043

Stewart, A. M., Braubach, O., Spitsbergen, J., Gerlai, R., and Kalueff, A. V. (2014). Zebrafish models for translational neuroscience research: from tank to bedside. Trends Neurosci. 37, 264-278. doi: 10.1016/j.tins.2014. 02.011

Streisinger, G., Walker, C., Dower, N., Knauber, D., and Singer, F. (1981). Production of clones of homozygous diploid zebra fish (Brachydanio rerio). Nature 291, 293-296. doi: 10.1038/291293a0

Trotha, J. W., Vernier, P., and Bally-Cuif, L. (2014). Emotions and motivated behavior converge on an amygdala-like structure in the zebrafish. Eur. J. Neurosci. 40, 3302-3315. doi: 10.1111/ejn.12692

Vargas, J. P., López, J. C., and Portavella, M. (2009). What are the functions of fish brain pallium? Brain Res. Bull. 79, 436-440. doi: 10.1016/j.brainresbull.2009.05.008

Woodruff, M. L. (2017). Consciousness in teleosts: there is something it feels like to be a fish. Anim. Sent. 13, 1-21. doi: 10.51291/2377-7478.1198

Wynne, C. D. L. (2001). Animal Cognition: The Mental Lives of Animals. Hampshire: Palgrave.

Conflict of Interest: The authors declare that the research was conducted in the absence of any commercial or financial relationships that could be construed as a potential conflict of interest.

Copyright (C) 2021 Luchiari, Málaga-Trillo, Tran and Gerlai. This is an open-access article distributed under the terms of the Creative Commons Attribution License (CC $B Y)$. The use, distribution or reproduction in other forums is permitted, provided the original author(s) and the copyright owner(s) are credited and that the original publication in this journal is cited, in accordance with accepted academic practice. No use, distribution or reproduction is permitted which does not comply with these terms. 